\title{
Glenohumeral Internal Rotation Deficit Measured in the Coronal and the Sagittal Planes in Baseball Players
}

\author{
Hiroaki Inui $^{1 *}$, Katsuya Nobuhara ${ }^{1}$ \\ ${ }^{1}$ Nobuhara Hospital \& Institute of Biomechanics
}

Received: July 15, 2016; Accepted: October 5, 2016; Published: October 22, 2016

*Corresponding author: Hiroaki Inui, Nobuhara Hospital \& Institute of Biomechanics, 720 Haze, Issaicho, Tatsunoshi, Hyogo 679-4017, Japan, Tel: 81-0791-66-0981; Fax: 81-0791-66-2687; Email: inuhiro123@yahoo.co.jp

\begin{abstract}
Baseball players exhibit more external rotation and less internal rotation at $90^{\circ}$ of abduction in their throwing shoulders. Posterior capsular tightness is often regarded as a cause of Glenohumeral Internal Rotation Deficit (GIRD); however, it remains unclear whether posterior capsular tightness affects glenohumeral range of motion. The objective of this study was to clarify the relationship between posterior capsular tightness and GIRD. We evaluated 214 male baseball players with competitive levels at an average age of $18 \pm 6$ years during 5 years (2010 to 20114). Subjects were divided into four groups: 28 elementary school boys (age, 9-12 years), 57 high school boys (age, 13-15 years), 71 high school boys (age, 16-18 years), and 58 adult (15 professional and 43 amateur) players (age, 19-28 years). We measured the glenohumeral angles of horizontal abduction, adduction, internal and external rotation in the coronal and sagittal planes with $90^{\circ}$ of abduction and compared the GIRD values in the two planes among the groups. Subjects were divided into two groups based on whether GIRD in the coronal plane exceeded $20^{\circ}$ and angular values were also compared between the two groups. In 15 players, the posterior capsule was evaluated using arthrography. Angles of adduction on the throwing sides were smaller than those on the non-throwing sides and this tendency was apparent in players $>15$ years of age. GIRD in the coronal plane showed no difference from that in the sagittal plane in each group. Subjects showing $\geq 20^{\circ}$ of GIRD in the coronal plane had lower GIRD values in the sagittal plane when the arm was horizontally adducted. Arthrography indicated that the posterior capsule was loose in the coronal plane even when the arm was internally rotated and that it stretched when the arm was horizontally adducted. GIRD in both planes indicated that posterior capsular tightness was not a cause of GIRD in the baseball players in our study.
\end{abstract}

Key Words: Baseball; Glenohumeral Internal Rotation Deficit; Posterior Tightness; Throwing Injuries;

\section{Introduction}

Baseball players commonly exhibit more external rotation and less internal rotation at $90^{\circ}$ of abduction in their throwing shoulders. The reason for the increase in external rotation and the decrease in internal rotation is believed to be an adaptation for achieving maximal arm position and creating maximum ball velocity. However, if the capsule was asymmetrically tight, it shifted the glenohumeral fulcrum, leading to throwing injuries $[3,4,5,6]$. After Tyler et al [17]. reported a correlation between GIRD and posterior shoulder tightness, posterior capsular tightness was often regarded as a primary cause of GIRD and excessive GIRD is considered to be a risk factor causing throwing injuries $[1,16]$. GIRD was generally evaluated with the arm at $90^{\circ}$ of abduction in the scapular plane. Angles of horizontal abduction or adduction which change during actual throwing motion could affect values of GIRD. Some authors have recommended that several clinical tests should be performed to identify a cause of GIRD (Nobuhara, 2003) [19]. The objective of this study was to determine effects of horizontal abduction or adduction on values of GIRD.

\section{Methods}

We evaluated 214 male players of various ages ranging from 9 to 37 years (mean age, $18 \pm 6$ years). This study was approved by our institutional review board. Written informed consent was obtained from all subjects before participating in the study.

The subjects consisted of four groups: group A, 28 elementary school boys (age, 9-12 years); group B, 57 junior high school boys (age, 13-15 years); group C, 71 high school boys (age, 16-18 years); and group D, 58 adult players that included 43 amateur baseball players and 15 professional baseball players (age, 19-28 years). The subjects were recruited from local competitive youth or school baseball teams. All adult players started to practice baseball less than ten years of age belonging to those competitive teams and were considered to have high skill levels. There were $179(84 \%)$ right hand dominant players and 35 (16\%) left hand dominant players. Subjects were excluded if they reported having a shoulder injury within the past year or shoulder pain at the time of testing.

Measurements were performed by three senior level physical therapists and subjects were randomly assigned to each examiner. Passive glenohumeral range of motion was assessed using a large goniometer. Angles of horizontal abduction, adduction, and internal and external rotation in the coronal and sagittal planes at 
$90^{\circ}$ of abduction were measured bilaterally. Measurements were recorded with each subject lying supine to stabilize the scapula. GIRD was calculated as the angular difference in internal rotation between the throwing and non-throwing sides. Subjects were divided into two groups based on whether GIRD in the coronal plane exceeded $20^{\circ}$ (group I, subjects with $<20$ degrees of GIRD and group II, subjects with $\geq 20^{\circ}$ of GIRD). Angular values were then compared between the two groups.

\section{Statistical analysis}

All data are expressed as mean and standard deviation and all statistical analyses were performed using Excell Statistics (SSRI Co., Tokyo, Japan). Side to side difference in each group was evaluated using the paired t-test, with $P<0.01$ considered statistically significant.

\section{Results}

Angles of external rotation in the coronal plane were $114 \pm$ $15^{\circ}$ on the throwing sides and $109 \pm 11^{\circ}$ on the non-throwing sides. Angles of external rotation in the sagittal plane were 108 $\pm 13^{\circ}$ on the throwing sides and $105 \pm 11^{\circ}$ on the non-throwing sides. Angles of internal rotation in the coronal plane were 44 $\pm 12^{\circ}$ on the throwing sides and $54 \pm 11^{\circ}$ on the non-throwing sides. Angles of internal rotation in the sagittal plane were 35 $\pm 14^{\circ}$ on the throwing sides and $45 \pm 14^{\circ}$ on the non-throwing sides. GIRD in the coronal plane showed no difference from that in the sagittal plane in each different age group (Table 1).

Subjects were divided into groups I and II based on whether GIRD exceeded $20^{\circ}$. In group II with $\geq 20$ degrees of GIRD in the coronal plane, GIRD decreased when the arm was adducted in the sagittal plane and there was a statistical difference between the values in the coronal and sagittal planes $\left(11^{\circ}\right.$, paired tests; $\mathrm{P}<0.0001$ ) (Table 2).

Angles of horizontal abduction were $32 \pm 26^{\circ}$ posterior to the coronal plane on the throwing sides and $32 \pm 28^{\circ}$ on the nonthrowing sides. Angles of horizontal adduction were $134 \pm 28^{\circ}$ anterior to the coronal plane on the throwing sides and $136 \pm 28^{\circ}$ on the non-throwing sides. Angles of adduction on the throwing sides were smaller than those on the non-throwing sides and this tendency was apparent in players $>15$ years of age $\left(3^{\circ}\right.$, paired $t$ tests; $\mathrm{P}=0.003$ ) (Table 3).

In both the groups of I and II, the angles of horizontal adduction on the throwing sides were smaller than those on the non-throwing sides (I: $2^{\circ}$, II: $3^{\circ}$, paired t tests; $\mathrm{P}=0.004,0.001$ ) (Table 4). Even though there were statistical differences in the angles of adduction between the sides, $2^{\circ}$ or $3^{\circ}$ might be of little clinical significance.

\section{Discussion}

Throwing athletes repeatedly demonstrate significantly increased glenohumeral external rotation and significantly decreased glenohumeral internal rotation in the throwing arm. The increase in external rotation is thought to be advantageous for achieving maximal arm position and creating maximum ball velocity and this shift in motion results in GIRD $[1,18]$. Thus, the reason for this shift in rotation in throwing athletes is believed to be an adaptation.

Humeral retrotorsion has been considered to be an important factor as a cause of GIRD. [2, 7, 12, 13, 20,7] showed that the timing of retrotorsion and GIRD coincided, suggesting that increased GIRD is caused by an increase in humeral retrotorsion between the limbs. Other authors also showed GIRD increases significantly between 13 and 14 years of age [10,11]. As far as average values were concerned, data from our different age groups were similar to those previous studies. We did not evaluate humeral retrotorsion because of difficulties in consistently evaluating humeral retrotorsion using computed tomography or ultrasound and could not determine whether GIRD was caused by humeral retrotorsion. However, if humeral retrotorsion were the only cause, values of GIRD evaluated in several planes might be consistent. When subjects were divided into two groups based on whether GIRD in the coronal plane exceeded $20^{\circ}, 26 \%$ of subjects showed more than $20^{\circ}$ of GIRD. The values of GIRD were

Table 1: Values of GIRD in the coronal and the sagittal planes among 4 groups.

\begin{tabular}{|c|c|c|c|}
\hline Group (N) & $\begin{array}{c}\text { GIRD } \\
\text { in the coronal } \\
\text { plane }\end{array}$ & $\begin{array}{c}\text { GIRD } \\
\text { in the sagittal } \\
\text { plane }\end{array}$ & P value \\
\hline A (28) & $6 \pm 12$ & $8 \pm 16$ & 0.59 \\
\hline B (57) & $10 \pm 13$ & $9 \pm 11$ & 0.50 \\
\hline C (71) & $12 \pm 12$ & $9 \pm 16$ & 0.15 \\
\hline D (58) & $10 \pm 12$ & $14 \pm 12$ & 0.06 \\
\hline
\end{tabular}

Table 2: Values of GIRD in the coronal and the sagittal planes among 2 groups

\begin{tabular}{|c|c|c|c|}
\hline Group (N) & $\begin{array}{c}\text { GIRD } \\
\text { in the coronal } \\
\text { plane }\end{array}$ & $\begin{array}{c}\text { GIRD } \\
\text { in the sagittal } \\
\text { plane }\end{array}$ & P value \\
\hline I (158) & $5 \pm 9$ & $8 \pm 13$ & 0.014 \\
\hline II (56) & $26 \pm 6$ & $15 \pm 16$ & $<0.0001$ \\
\hline
\end{tabular}

\begin{tabular}{|c|c|c|c|c|c|c|}
\hline \multicolumn{6}{|c|}{ Table 3: Values of horizontal abduction and adduction among 4 groups } \\
\hline \multirow{2}{*}{ Group (N) } & \multicolumn{3}{|c|}{ ABD } & \multicolumn{3}{c|}{ ADD } \\
\cline { 2 - 7 } & r & l & P value & r & $\mathbf{l}$ & P value \\
\hline A (28) & $27 \pm 11$ & $28 \pm 11$ & 0.58 & $141 \pm 11$ & $145 \pm 10$ & 0.01 \\
\hline B (57) & $27 \pm 9$ & $27 \pm 9$ & 0.62 & $141 \pm 11$ & $143 \pm 10$ & 0.05 \\
\hline C (71) & $27 \pm 9$ & $26 \pm 9$ & 0.28 & $139 \pm 10$ & $142 \pm 8$ & 0.003 \\
\hline D (58) & $24 \pm 11$ & $24 \pm 8$ & 0.82 & $139 \pm 10$ & $142 \pm 7$ & 0.003 \\
\hline
\end{tabular}

Table 4: Values of horizontal abduction and adduction among 2 groups.

\begin{tabular}{|c|c|c|c|c|c|c|}
\hline \multirow{2}{*}{ Group (N) } & \multicolumn{3}{|c|}{ ABD } & \multicolumn{3}{c|}{ ADD } \\
\cline { 2 - 8 } & r & 1 & P value & r & 1 & P value \\
\hline I(158) & $30 \pm 21$ & $30 \pm 23$ & 0.48 & $136 \pm 24$ & $138 \pm 23$ & 0.004 \\
\hline II(56) & $38 \mathrm{a} \pm 37$ & $37 \pm 39$ & 0.70 & $128 \pm 37$ & $131 \pm 38$ & 0.0012 \\
\hline
\end{tabular}


different between in the coronal and sagittal planes, indicating asymmetric tension in their joints existed. This could become an important factor influencing injury risk in the arm.

Increased thickness of the posterior capsule in throwing athletes is seen frequently during arthroscopy and with ultrasound scans $[1,14,15,21]$. This thickening of the posterior capsule is believed to occur from repetitive micro trauma sustained during the deceleration phase. Harryman et al [6] showed that tightness in the posterior capsule results in anterosuperior migration of the humeral head on the glenoid. Other authors have also suggested that posterior capsular contracture shifts the glenohumeral fulcrum, leading to throwing injuries $[4,5,8]$. After Tyler showed a close relation between GIRD and limitation of shoulder cross body adduction, it was often believed that GIRD resulted primarily from posterior capsular tightness $[1,11]$.

Subjects with $\geq 20^{\circ}$ of GIRD showed a smaller magnitude of GIRD in the sagittal plane compared with that in the coronal plane. If GIRD resulted primarily from thickening of the posterior capsule, the magnitude of GIRD in the sagittal plane would be larger than that in the coronal plane because the posterior capsule was tighter when the arm was adducted in the sagittal plane. To explain the discrepancy between the values in the two planes, it is reasonable to consider that anterior rather than posterior side of their joints was affected.

There were several limitations in this study. Only ranges of motion of healthy players were evaluated in this study and severe cases with posterior capsule tightness may not have been included; therefore, our results cannot be compatible with an injured population. Even though we recruited competitive players for evaluation, their skill levels inevitably were varying from amateur to professional levels. However, subjects in this study might reflect a population general sports doctors or shoulder surgeons examine on a daily basis. Also, three physical therapists measured passive range of motion and end range was not quantified. To exclude inter examiner error, only side to side difference in each subject was evaluated in the study. Assessing passive range of motion on a clinical situation might contain other errors like pain affecting its measurements and changes of 5 to 10 degrees reportedly were meaningful [9]. The difference of GIRD between in the coronal and the sagittal planes exceeded 10 degrees on average while the difference in horizontal adduction angle was only 3 degrees on average. Assessment of GIRD in the two positions can easily be done by one examiner and would be useful for ruling out posterior capsular tightness which we think is difficult to detect on clinical basis.

\section{Conclusions}

Twenty-six percent of the subjects showed different values of GIRD in the coronal and sagittal planes. Subjects with $\geq 20^{\circ}$ of GIRD in the coronal plane showed a smaller magnitude of GIRD in the sagittal plane indicating posterior shoulder tightness did not cause GIRD.

\section{Conflict of interest}

None.

\section{References}

1. Burkhart SS, Morgan CD, Kibler WB. The disabled throwing shoulder: spectrum of pathology Part I: pathoanatomy and biomechanics. Arthroscopy. 2003;19: 404-420. DOI:10.1053/jars.2003.50128.

2. Crockett HC, Gross LB, Wilk KE, Schwartz ML, Reed J, O’Mara J, et al. Osseous adaptation and range of motion at the glenohumeral joint in professional baseball pitchers. Am J Sports Med.2002;30(1): 20-26.

3. Dines JS, Frank JB, Akerman M, Yocum LA . Glenohumeral internal rotation deficits in baseball players with ulnar collateral ligament insufficiency. Am J Sports Med. 2009;37: 566-70. doi: 10.1177/0363546508326712.

4. Gates JJ, Gupta A, McGarry MH, Tibone JE, Lee TQ. The effect of glenohumeral internal rotation deficit due to posterior capsular contracture on passive glenohumeral joint motion. Am J Sports Med. 2012; 40(12): 2794-800. doi: 10.1177/0363546512462012.

5. Grossman MG, Tibone JE, McGarry MH, Schneider DJ, Veneziani S, Lee TQ. A cadaveric model of the throwing shoulder: a possible etiology of superior labrum anterior-to-posterior lesions. J Bone Joint Surg Am. 2005;87(4): 824-831.

6. Harryman DT 2nd, Sidles JA, Clark JM, McQuade KJ, Gibb TD, Matsen FA $3^{\text {rd }}$. Translation of the humeral head on the glenoid with passive glenohumeral motion. J Bone Joint Surg Am. 1990;72: 1334-1343.

7. Hibberd EE, Oyama S, Myers JB. Increase in humeral retrotorsion accounts for age-related increase in glenohumeral internal rotation deficit in youth and adolescent baseball players. Am J Sports Med. 2014;42: 851-858. doi: 10.1177/0363546513519325.

8. Huffman GR, Tibone JE, McGarry MH, Phipps BM, Lee YS, Lee TQ. Path of glenohumeral articulation throughout the rotational range of motion in a thrower's shoulder model. Am J Sports Med. 2006;34(10): 1662-1669.

9. Kibler WB, Sciascia A, Thomas SJ. Glenohumeral internal rotation deficit: pathogenesis and response to acute throwing. Sports Med Arthrosc. 2012;20(1):34-38. doi: 10.1097/JSA.0b013e318244853e.

10. Levine WN, Brandon ML, Stein BS, Gardner TR, Bigliani LU, Ahmad CS. Shoulder adaptive changes in youth baseball players. J Shoulder Elbow Surg. 2006;15(5): 562-566. DOI:10.1016/j.jse.2005.11.007.

11. Meister K, Day T, Horodyski M, Kaminski TW, Wasik MP, Tillman S. Rotational motion changes in the glenohumeral joint of the adolescent/ Little League baseball player. Am J Sports Med. 2005;33(5): 693-698. DOI:10.1177/0363546504269936.

12. Pieper HG. The shoulder: Its function and clinical aspects, World Scientific Publishing. Humeral torsion in the throwing arm of handball players. Am J Sports Med. 1998; 26(2): 247-253.

13. Reagan KM, Meister K, Horodyski MB, Werner DW, Carruthers C, Wilk K. Humeral retroversion and its relationship to glenohumeral rotation in the shoulder of college baseball players. Am J Sports Med. 2002;30(3): 354-360.

14. Thomas SJ, Swanik CB, Higginson JS, Kaminski TW, Swanik KA, Bartolozzi AR, et al. A bilateral comparison of posterior capsule thickness and its correlation with glenohumeral range of motion and scapular upward rotation in collegiate baseball players. J Shoulder Elbow Surg. 2011;20(5):708-716. doi: 10.1016/j.jse.2010.08.031.

15. Ticker JB, Beim GM, Warner JJ. Recognition and treatment of refractory posterior capsular contracture of the shoulder. Arthroscopy. 2000;16(1): 27-34. 
16. Tyler TF, Nicholas SJ, Roy T, Gleim GW. Quantification of posterior capsule tightness and motion loss in patients with shoulder impingement. Am J Sports Med. 2000; 28(5): 668-673.

17. Tyler TF, Roy T, Nicholas SJ, Gleim GW. Reliability and validity of a new method of measuring posterior shoulder tightness. J Orthop Sports Phys Ther. 1999;29(5):262-269; discussion 270-274. DOI:10.2519/ jospt.1999.29.5.262.

18. Werner SL, Gill TJ, Murray TA, Cook TD, Hawkins RJ. Relationships between throwing mechanics and shoulder distraction in professional baseball pitchers. Am J Sports Med. 2001;29(3): 354-358.
19. Wilk KE, Meister K, Andrews JR. Current concepts in the rehabilitation of the overhead throwing athlete. Am J Sports Med. 2002;30(1): 136151.

20. Yamamoto N, Itoi E, Minagawa H, Urayama M, Saito H, Seki N, et al. Why is the humeral retroversion of throwing athletes greater in dominant shoulders than in nondominant shoulders? J Shoulder Elbow Surg. 2006;15(5):571-575. DOI:10.1016/j.jse.2005.06.009.

21. Yoneda M, Nakagawa S, Mizuno N, Fukushima S, Hayashida K, Mae T, et al. Arthroscopic capsular release for painful throwing shoulder with posterior capsular tightness. Arthroscopy.2006;22(7): 801 e1-5. 